\title{
The prevalence of asthma and asthma-like symptoms among adults in rural Beijing, China
}

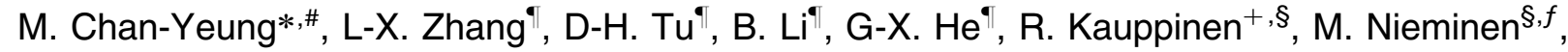 \\ D.A. Enarson**
}

The prevalence of asthma and asthma-like symptoms among adults in rural Beijing, China. M. Chan-Yeung, L-X. Zhang, D-H. Tu, B. Li, G-X. He, R. Kauppinen, M. Nieminen, D. A. Enarson. C) ERS Journals Ltd 2002.

ABSTRACT: No data have been reported on the prevalence of asthma in rural areas of China. The objective of the present study was to determine the prevalence of asthmalike symptoms, reported asthma and reported asthma attacks in rural Beijing, China, and to compare the prevalence in 20-44-yr-old participants with those reported for Canada and the European Community Respiratory Health Survey (ECRHS).

For a cross-sectional survey, 30 villages were randomly selected in the counties of Shunyi and Tongxian, $50 \mathrm{~km}$ north and east respectively of the city of Beijing and within the municipality of Beijing. The International Union Against Tuberculosis and Lung Disease questionnaire on bronchial symptoms translated into Chinese was completed by village doctors for each individual of $>15$ yrs. The survey was completed by 22,561 individuals, representing $98 \%$ of the eligible population.

The prevalence of asthma-like symptoms and reported asthma attacks was higher in females than in males and increased with age. Smoking significantly increased the prevalence of symptoms; the effect in females was greater than in males. Among the 20-44-yr-olds, the prevalence of reported asthma attacks in the previous 12 months was $0.67 \%$ in rural Beijing, very much lower than that reported in ECRHS centres (3.1\%), urban Canada $(6.9 \%)$ and semirural Canada $(5.1 \%)$, after adjusting for age and sex. The prevalence of asthma-like symptoms was also very low in rural Beijing compared with ECRHS centres and Canada.

It is concluded that the prevalence of asthma-like symptoms and reported asthma was low in rural China compared with other countries, consistent with reports of the relative scarcity of asthma in farms and the "hygiene hypothesis".

Eur Respir J 2002; 19: 853-858.

\begin{abstract}
*University of British Columbia Vancouver, Canada. "\#niversity of Hong Kong, Hong Kong, China. 'Beijing Research Institute for Tuberculosis Control, Beijing, China. ${ }^{+}$South Karelia Hospital, Lappeenranta, Finland. ${ }^{\S}$ Finnish Lung Health Association, Helsinki, Finland. ${ }^{f}$ Tampere University Hospital, Tampere, Finland. **International Union Against Tuberculosis and Lung Disease, Paris, France.
\end{abstract}

Correspondence: M. Chan-Yeung, Dept of Medicine, The University of Hong Kong, Queen Mary Hospital, Hong Kong, SAR, China.

Fax: 85228551143

E-mail: mmwchan@hku.hk

Keywords: Asthma

asthma-like symptoms

China

prevalence

rural Beijing

Received: June 52001

Accepted after revision December 10 2001
The development of a standardized questionnaire by the International Union Against Tuberculosis and Lung Disease (IUATLD) has allowed comparison of the prevalence of asthma and asthma-like symptoms in adults in different countries [1]. It was utilized in the European Community Respiratory Health Survey (ECHRS), involving 48 centres in 17 European and five non-European countries between 1990-1995 [2]. A study of six communities across Canada was also carried out using the same questionnaire [3]. The prevalence of asthma was found to vary not only among countries but also within a country as large as Canada [3]. The prevalence of asthma and asthmalike symptoms is higher in industrialized countries than in developing countries [2,4]. The prevalence of asthma and asthma-like symptoms has been reported among children in urban areas of China as part of the International Study of Asthma and Allergies in Childhood (ISAAC) [4]. However, no data have been reported on the epidemiology of asthma in rural areas, which encompass $>80 \%$ of the 1.2 billion population of the People's Republic of China.

The purpose of this study was to determine the prevalence of reported asthma, reported asthma attacks and asthma-like symptoms in adults of $>15 \mathrm{yrs}$ in the rural counties of Beijing municipality and to compare the prevalence among participants aged 20-44 yrs with those of similar populations reported in Canada and ECHRS centres.

\section{Subjects and methods}

\section{Study design}

A cross-sectional survey was carried out on all individuals of $\geqslant 15 \mathrm{yrs}$ resident in 30 randomly selected villages of the counties of Shunyi and Tongxian, $50 \mathrm{~km}$ north and east respectively of the city of Beijing, China. The study was carried out between 1996-1997.

\section{Methods}

The village doctor visited every household in the village and all individuals of $\geqslant 15$ yrs were invited to take part in the study. The village doctor conducted 
an interview using a Chinese translation of the IUATLD questionnaire on bronchial symptoms which had been validated and subsequently used extensively as the postal questionnaire of the ECRHS [1]. There were also questions on smoking. The questionnaire was translated into Chinese and back-translated into English to ensure accuracy. A workshop, organized by the Beijing Research Institute for Tuberculosis Control, the University of British Columbia, the IUATLD and the Finnish Lung Health Association, was held prior to the survey in order to train the village doctors in the correct completion of the questionnaire. The survey was constantly supervised and regularly monitored by specialist doctors from the Beijing Research Institute for Tuberculosis Control.

The following symptoms and questions were used in the analysis (in the same way as in the ECRHS [2]). 1) Wheeze: "Have you had wheezing or whistling in your chest at any time in the last 12 months?" 2) Chest tightness: "Have you woken up with a feeling of tightness in your chest at any time in the last 12 months?" 3) Nocturnal shortness of breath: "Have you been woken by an attack of shortness of breath at any time in the last 12 months?" 4) Nocturnal cough: "Have you been woken by an attack of coughing at any time in the last 12 months?" 5) Asthma attack: "Have you had an attack of asthma in the last 12 months?" 6) Asthma medication: "Are you currently taking any medication (including inhalers, aerosols or tablets) for asthma?" 7) Chronic cough: "Do you usually have cough first thing in the morning or during the day?" and "Do you cough like this for as much as 3 months each year?" 8) Chronic phlegm: "Do you usually have phlegm first thing in the morning or during the day?" and "Do you usually have phlegm like this for as much as 3 months each year?"

Current smokers were defined as those who were still smoking within 1 month before completing the questionnaire, nonsmokers were those who were lifelong nonsmokers and exsmokers the remainder.

\section{Analysis}

The survey was completed by 22,561 individuals, representing $98 \%$ of the population of $>15 \mathrm{yrs}$.
Thirty-three questionnaires were incomplete and so excluded from the analysis. The results of 22,528 individuals are analysed in the present report. Sexspecific prevalence rates with exact $95 \%$ confidence intervals were estimated for all participants and for each 10-yr age group. Logistic regression analysis was employed to assess the effects of age, sex and smoking habit on respiratory symptoms.

In the comparison of the present results with those of the ECRHS, only individuals aged 20-44 yrs were included. The prevalence of each symptom was adjusted for a population with a standard distribution of age and sex, without adjustment for nonresponse $[2,5]$.

\section{Ethics}

The study was approved by the Ethics Committee of the University of British Columbia. All participants were assured that all personal information concerning their health status would be kept confidential and that information would be provided to a third party only on written request from them. Any participant known to have abnormalities of consequence to their health was advised to permit this information to be provided to their village doctor to assist in further care. All patients with evidence suggestive of asthma were investigated further and those found to have asthma were offered treatment.

\section{Results}

Table 1 shows the distribution of the population by age, sex and smoking habit. There were more males in the younger age groups but more females in the older age groups. Overall, only $4.4 \%$ of females but $55 \%$ of males were current smokers. There were relatively few exsmokers.

The prevalence of asthma-like symptoms and selfreported asthma attacks and the reported use of asthma medications during the preceding 12 months are shown separately for males and females in tables 2 and 3 . In males, the prevalence of wheeze increased

Table 1. - Characteristics of study population by age group

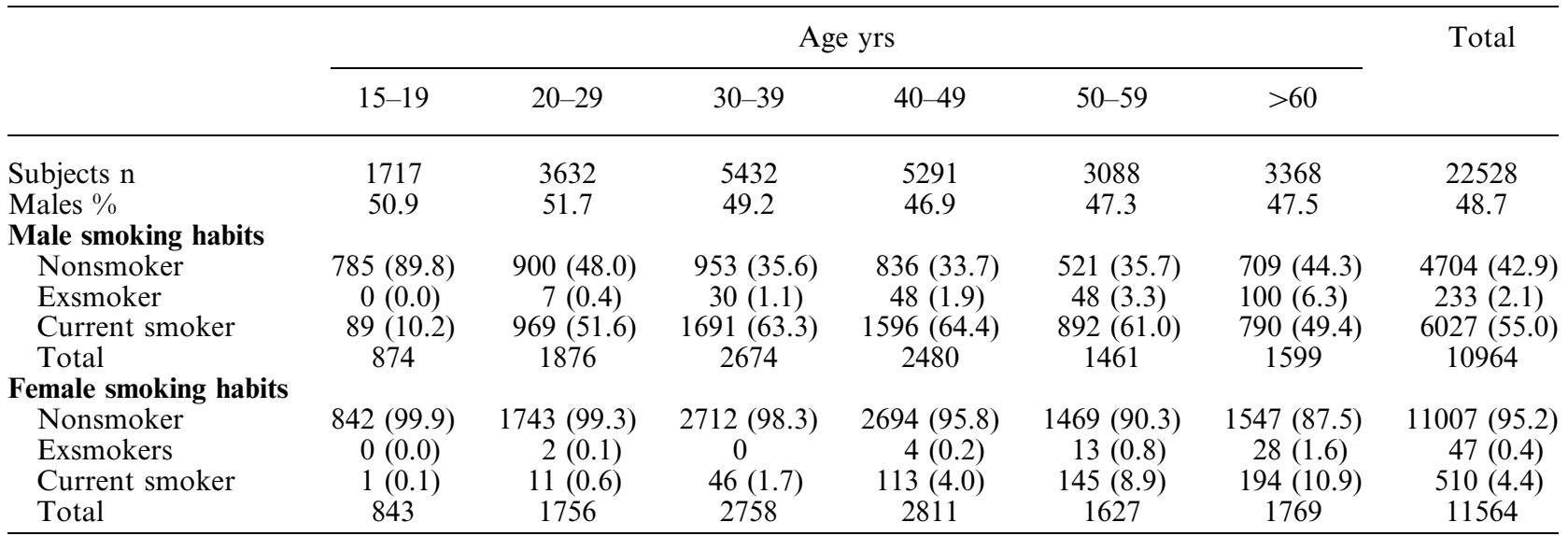

Smoking habit data are presented as $\mathrm{n}(\%)$. 
Table 2. - Prevalence of asthma symptoms, self-reported asthma and chronic bronchitis in males by age group*

\begin{tabular}{|c|c|c|c|c|c|c|c|}
\hline & \multicolumn{6}{|c|}{ Age yrs } & \multirow[t]{2}{*}{ Total } \\
\hline & $15-19$ & $20-29$ & $30-39$ & $40-49$ & $50-59$ & $>60$ & \\
\hline Wheezing & $.5(0.2-0.7)$ & $0.6(0.4-0.8)$ & $1.0(0.8-1.2)$ & $1.8(1.6-2.0)$ & $3.8(3.4-4.2)$ & $8.4(7.9-9.0)$ & $2.5(2.4-2.6)$ \\
\hline Chest tightness & $0.1(0.0-0.3)$ & $0.4(0.2-0.5)$ & $0.8(0.6-0.9)$ & $1.4(1.2-1.6)$ & $2.6(2.2-2.9)$ & $4.8(4.4-5.2)$ & $1.6(1.5-1.6)$ \\
\hline Nocturnal SOB & $0.1(0.0-0.3)$ & $0.1(0.0-0.2)$ & $0.5(0.4-0.6)$ & $0.7(0.6-0.8)$ & $2.7(2.3-3.0)$ & $3.8(3.4-4.2)$ & $1.2(1.1-1.3)$ \\
\hline Nocturnal cough & $0.5(0.2-0.7)$ & $0.9(0.7-1.0)$ & $1.1(0.9-1.3)$ & $2.7(2.5-3.0)$ & $4.0(3.6-4.4)$ & $6.4(5.9-6.8)$ & $2.5(2.4-2.7)$ \\
\hline $\begin{array}{l}\text { Self-reported asthma } \\
\text { attack }\end{array}$ & $0.2(0.1-0.5)$ & $0.3(0.2-0.5)$ & $0.6(0.4-0.7)$ & $1.0(0.8-1.2)$ & $2.5(2.2-2.9)$ & $6.4(5.9-6.8)$ & $1.7(1.6-1.8)$ \\
\hline Asthma medication & $0(0.0-0.2)$ & $0.2(0.1-0.3)$ & $0.5(0.4-0.6)$ & $0.7(0.5-0.8)$ & $1.6(1.3-1.9)$ & $5.0(4.6-5.4)$ & $1.2(1.2-1.3)$ \\
\hline
\end{tabular}

*: in the previous 12 months. Data are presented as percentages with $95 \%$ confidence intervals in parentheses. SOB: shortness of breath. $\mathrm{p}<0.01$ between age groups for all symptoms (Chi-squared test).

Table 3. - Prevalence of asthma symptoms, self-reported asthma and chronic bronchitis in females by age groups*

\begin{tabular}{lrcccccc}
\hline & \multicolumn{9}{c}{ Age yrs } & & Total \\
\cline { 2 - 6 } & \multicolumn{1}{c}{$15-19$} & $20-29$ & $30-39$ & $40-49$ & $50-59$ & $>60$ \\
\hline Wheezing & $0(0.0-0.2)$ & $0.4(0.2-0.6)$ & $1.3(1.2-1.5)$ & $2.6(2.3-2.8)$ & $4.4(4.0-4.8)$ & $7.0(6.5-7.5)$ & $2.72 .6-2.8$ \\
Chest tightness & $0.4(0.1-0.6)$ & $0.6(0.4-0.8)$ & $1.4(1.2-1.6)$ & $1.9(1.7-2.1)$ & $2.5(2.1-2.8)$ & $3.7(3.4-4.1)$ & $1.81 .7-1.9$ \\
Nocturnal SOB & $0(0.0-0.2)$ & $0.3(0.2-0.5)$ & $0.9(0.7-1.1)$ & $1.4(1.2-1.6)$ & $2.3(2.0-2.6)$ & $3.6(3.3-4.0)$ & $1.5(1.4-1.6)$ \\
Nocturnal cough & $0.5(0.2-0.8)$ & $0.8(0.6-1.0)$ & $1.7(1.5-1.9)$ & $2.3(2.1-2.6)$ & $4.5(4.1-4.9)$ & $5.7(5.3-6.1)$ & $2.6(2.5-2.7)$ \\
Self-reported asthma & $0(0.0-0.2)$ & $0.4(0.2-0.6)$ & $0.8(0.6-0.9)$ & $2.0(1.8-2.2)$ & $3.4(3.0-3.7)$ & $5.4(5.0-5.8)$ & $2.0(1.9-2.1)$ \\
$\quad \begin{array}{l}\text { attack } \\
\text { Asthma medication }\end{array}$ & $0(0.0-0.2)$ & $0.3(0.2-0.4)$ & $0.6(0.4-0.7)$ & $1.2(1.0-1.4)$ & $2.6(2.3-2.9)$ & $4.5(4.1-4.8)$ & $1.5(1.4-1.6)$ \\
\hline
\end{tabular}

*: in the previous 12 months. Data are presented as percentages with $95 \%$ confidence intervals in parentheses. SOB: shortness of breath. $\mathrm{p}<0.01$ between age groups for all symptoms (Chi-squared test).

from $0.5 \%$ in those aged $15-19$ yrs to $8.4 \%$ in those aged $>60$ yrs and from 0 to $7 \%$ in females. The prevalence of all other symptoms also increased with age. The mean prevalence of wheeze was $2.7 \%$ and that of reported asthma attacks in the past 12 months $2 \%$.

The prevalence of chronic cough and chronic phlegm in nonsmokers and smokers according to cumulative tobacco consumption are presented in table 4. There is a dose/response relationship between the prevalence of symptoms and the amount smoked. The prevalence of chronic phlegm was $1 \%$ in nonsmokers and $9.4 \%$ in those who had a tobacco consumption of $>30$ pack-yrs.

The effects of age, sex and smoking on the prevalence of the reported symptoms are shown in table 5 . Age, sex and smoking were significant predictors of the prevalence of each of the symptoms. Those aged $>60$ yrs showed 7-15 times the prevalence of the various symptoms compared to those aged $<30 \mathrm{yrs}$. Females had a significantly greater risk of symptoms compared with males even after adjusting for differences in age and smoking habits. When the analysis was carried out on nonsmokers only, the significant age relationship persisted.

Table 6 compares the demographical data of the individuals in the present study aged 20-44 yrs with those in the one semirural (Prince Edward Island) and five urban communities in Canada. There were significant differences in the distribution of age and sex between the three populations.

Figure 1 shows a comparison of the prevalence of selected symptoms (adjusted for age and sex) between those in rural Beijing, the urban centres in Canada, the semirural centre in Canada and the centres that participated in the ECRHS. The symptoms compared were wheeze, being awakened by chest tightness and cough, self-reported asthma attacks and use of asthma medication in the last 12 months. The prevalence of each of the symptoms was substantially lower in the rural Beijing population compared to the Canadian communities, including the semirural community, and the centres that took part in the ECRHS. For example, the prevalence of wheeze was $1.1 \%$ in Beijing, $20.7 \%$ in the ECRHS, $27.7 \%$ in urban Canada and $26.4 \%$ in semirural Canada and the prevalence of

Table 4. - Prevalence of chronic cough and chronic phlegm by cumulative tobacco consumption

\begin{tabular}{lllllll}
\hline & Nonsmoker & $<10$ pack-yrs & $10-19$ pack-yrs & $20-29$ pack-yrs & $>30$ pack-yrs & Total \\
\hline Chronic cough & $1.0(1.0-1.1)$ & $1.9(1.7-2.1)$ & $2.5(2.2-2.8)$ & $4.6(4.1-5.0)$ & $9.4(8.7-10.0)$ & $1.9(1.9-2.0)$ \\
Chronic phlegm & $1.0(1.0-1.1)$ & $1.8(1.6-2.0)$ & $2.5(2.2-2.8)$ & $4.7(4.2-5.1)$ & $9.2(8.6-9.8)$ & $1.9(1.8-1.9)$ \\
\hline
\end{tabular}

Data are presented as percentages with $95 \%$ confidence intervals in parentheses. 
Table 5. -Effects of age and sex on prevalence of selected symptoms*

\begin{tabular}{lcccc}
\hline & Wheeze & Chest tightness & Nocturnal cough & Self-reported asthma attack \\
\hline $\begin{array}{l}\text { Female sex } \\
\text { Smoking habits }\end{array}$ & $1.75(1.41-2.16)$ & $1.43(1.11-1.85)$ & $1.76(1.42-2.18)$ & $1.82(1.42-2.33)$ \\
$\quad$ Exsmoker & $10.43(7.42-14.69)$ & $7.73(5.18-11.5)$ & $9.52(6.66-13.6)$ & $10.9(7.53-15.8)$ \\
$\quad$ Smoker & $2.17(1.74-2.71)$ & $1.35(1.02-1.78)$ & $2.33(1.86-2.91)$ & $1.80(1.38-2.35)$ \\
Age group yrs & & & & \\
30-39 & $2.47(1.53-3.98)$ & $2.51(1.54-4.11)$ & $1.78(1.21-2.64)$ & $2.22(1.22-4.06)$ \\
$40-49$ & $4.50(2.87-7.06)$ & $3.80(2.37-6.08)$ & $3.11(2.16-4.47)$ & $4.90(2.82-8.52)$ \\
$50-59$ & $7.96(5.07-12.48)$ & $5.47(3.39-8.83)$ & $5.03(3.48-7.26)$ & $8.95(5.16-15.5)$ \\
$>60$ & $15.02(9.75-23.15)$ & $8.82(5.49-13.92)$ & $6.94(4.87-9.89)$ & $17.15(10.08-29.2)$ \\
\hline
\end{tabular}

*: in the previous 12 months. Data are presented as odds ratios with $95 \%$ confidence intervals in parentheses. The multiple logistic regression model was female versus male exsmokers versus nonsmokers and current smokers versus nonsmokers; all age groups were compared separately with those aged $<30 \mathrm{yrs}$.

Table 6. - Comparison of demographic data of 20-40-yrold populations in rural China and Canada

\begin{tabular}{lccc}
\hline & $\begin{array}{c}\text { Rural } \\
\text { China }\end{array}$ & $\begin{array}{c}\text { Urban } \\
\text { Canada }\end{array}$ & $\begin{array}{c}\text { Semirural } \\
\text { Canada (PEI) }\end{array}$ \\
\hline Subjects n & 11817 & 15362 & 3338 \\
Males & $5864(49.6)$ & $6753(44.0)$ & $1609(48.2)$ \\
Age yrs & $33.4 \pm 6.7$ & $32.3 \pm 7.1$ & $33.2 \pm 6.6$ \\
Age group yrs & & & \\
$\quad 20-24$ & $1306(11.1)$ & $2578(16.8)$ & $438(13.1)$ \\
$25-29$ & $2326(19.7)$ & $3189(20.8)$ & $585(17.5)$ \\
30-34 & $2665(22.6)$ & $3487(22.6)$ & $816(24.5)$ \\
35-39 & $2767(23.4)$ & $3068(20.0)$ & $751(22.5)$ \\
40-44 & $2753(23.3)$ & $3040(19.8)$ & $748(22.4)$ \\
Smoking habits & & & \\
$\quad$ Nonsmokers & $8134(68.6)$ & $6652(43.4)$ & $1354(40.7)$ \\
Exsmokers & $72(0.6)$ & $3895(25.4)$ & $920(27.7)$ \\
Current smokers & $3611(30.6)$ & $4779(31.2)$ & $1051(31.6)$ \\
\hline
\end{tabular}

Data are presented as mean \pm SD or $\mathrm{n}(\%)$. PEI: Prince Edward Island.

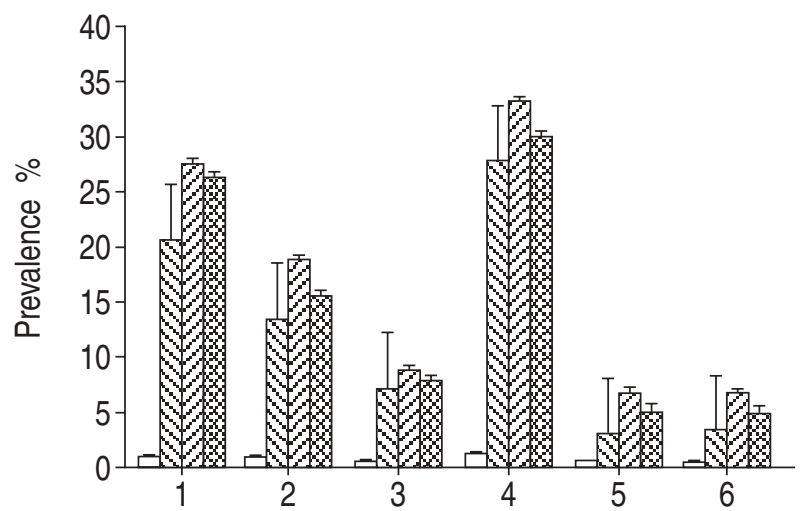

Fig. 1.-Comparison of the prevalence of selected symptoms (adjusted for age and sex) in rural Beijing ( $\square$ ), the urban centres in Canada (ש) , the semirural centre in Canada (Prince Edward Island; and the centres that participated in the European Community Respiratory Health Survey (ECRHS; $\mathbb{\$}$ ): 1) wheeze; 2) chest tightness; 3 ) nocturnal shortness of breath; 4) nocturnal cough; 5) asthma attack; and 6) asthma medication in the last 12 months. The vertical bars represent the upper $95 \%$ confidence interval for data from rural Beijing and Canada and 75th percentile for ECRHS data. reported asthma attacks in the last 12 months 0.67 , $3.1,6.9$ and $5.1 \%$ respectively.

\section{Discussion}

There have been relatively few studies using a standardized questionnaire to determine the prevalence of asthma symptoms, reported asthma attacks and chronic respiratory symptoms in adults in China. The use of a standardized questionnaire has allowed comparisons with results obtained using the same questionnaire in other countries. The most striking finding of this study is the very low prevalence of asthma-like symptoms, self-reported asthma attacks and use of medications for asthma among 20-44-yrolds in rural Beijing compared to the one semirural and five urban centres in Canada [3] and the centres that took part in the ECRHS [2].

The low level of reported symptoms in the present study might be due to misunderstanding of the questions. In order to demonstrate the validity of the findings, the relationship between cumulative tobacco consumption and prevalence of symptoms was investigated. The expected dose/response relationship between the amount smoked and the prevalence of symptoms was found, suggesting that the translated questionnaire was satisfactorily understood by the participants. Although challenge testing for nonallergic bronchial hyperresponsiveness was not performed because of the lack of facilities in the rural areas, the Chinese version of the ISAAC questionnaire has been validated by bronchial hyperresponsiveness testing in Chinese schoolchildren [4]. The same questionnaire has been used to compare the prevalence of respiratory and atopic disorders in Chinese schoolchildren in three cities in China, Hong Kong, Guangzhou and Beijing [5]. There is only one written language in China and the questionnaire was well understood by children and parents alike in the three cities. The words used for wheeze, cough, chest tightness and asthma in the Chinese version of the ISAAC questionnaire were the same as those in the Chinese version of the IUATLD questionnaire used in the present study.

The results of this study are consistent with those 
reported for the ISAAC study of 13-14-yr-olds, carried out in 156 centres in 56 countries [6], including five centres in China. Estimates from the centres in China, using a self-completed questionnaire, of the prevalence of wheeze in the previous 12 months were $4.2 \%$ (range $3.3-5.1 \%$ ) and wheeze that disturbs sleep $0.3 \%(0.2-0.3 \%)$, whereas estimates for other countries in this geographical region were remarkably higher at 8.0 and $0.6 \%$ respectively and globally 13.8 and $1.7 \%$ respectively. Estimates from the video questionnaire for the prevalence of wheeze in the previous 12 months were even lower, ranging $1.3-3.3 \%$ for the centres in China, whereas the global mean was $7.3 \%$.

The low prevalence of asthma-like symptoms and reported asthma in rural areas in China is consistent with recent reports of the scarcity of asthma and atopy among children raised on farms in several countries [7-11]. It has been postulated that the lifestyle associated with living on a farm (larger family size, more pets, heating frequently using wood or coal, less maternal smoking and more dampness) may be responsible for the low prevalence. Contact with animals was shown to explain much of the inverse relationship between farming and atopy in the Austrian study [10]. Endotoxin and lipopolysaccharide in the farm environment may bind to the CD14 receptor, resulting in the increased production of interleukin-12, which activates the type $1 \mathrm{~T}$-helper lymphocyte pathway [12, 13]. In the villages outside the city of Beijing, most families keep some livestock and poultry in the yard. This may be one of the major reasons for the low prevalence of asthma in the 20-44-yr-olds who have spent their whole life in this environment and is consistent with the "hygiene hypothesis" [14]. The present study did not investigate young adults in urban areas in Beijing for comparison of urban/rural differences. Such a study is currently being carried out on schoolchildren.

The low prevalence of reported asthma could be due to poor knowledge of health, poor health services or a lack of diagnostic facilities. However, the present community-based survey was independent of the utilization of health services. As the participation rate was $>98 \%$, it is unlikely that there has been a bias due to nonresponse. Moreover, the villages included in the study were randomly selected from all the villages of the two counties and should be representative of the overall population of the area.

One of the major findings of the ISAAC study was the wide variation in the prevalence of asthma and other allergic diseases among countries participating in the study. The rates in Hong Kong and Guangzhou, which are close geographically and have the same language and predominant ethnic group, were very different. Hong Kong, the more affluent city, had a prevalence of asthma attacks in the last 12 months of $10.1 \%$ compared to $2.0 \%$ in Guangzhou, the less affluent city [6]. The higher frequency of asthma in schoolchildren in Hong Kong compared to other Chinese cities was confirmed in a later study [5]. Another study of Chinese schoolchildren (aged 12-18 yrs) in Southeast Asia has shown considerable variation in the prevalence of asthma and allergic diseases [15]. The prevalence of "asthma ever" was greatest in Hong Kong $(6.6 \%)$, lowest in $\mathrm{San} \mathrm{Bu}$ in Southern China (1.6\%) and intermediate in Kota Kinabalu in Malaysia (3.3\%). The prevalence of atopy, defined as a positive skin test to one or more common aeroallergens, was 58, 64 and $40 \%$ respectively, indicating that the differences in the prevalence of asthma and asthma symptoms could not be explained by differences in atopic sensitization.

In the present study, it was found that age, sex and smoking habits are important independent determinants of the prevalence of the respiratory symptoms investigated in rural China. The strong positive relationship with age is not explained by tobacco smoking as it was also present in nonsmokers. This relationship suggests that there may be risk factors other than smoking that are important determinants of respiratory symptoms, possibly indoor and/or outdoor air pollution. The villages are situated $\sim 50 \mathrm{~km}$ to the north and east of the city of Beijing. The city is known to have relatively high levels of atmospheric pollution associated with vehicle emissions as well as using coal as a major source of heat. In addition, as a proportion of families use corn-stalk and biomass for supplementation of other types of fuel such as gas, wood and coal, there is likely to be substantial indoor air pollution as well. The scope of this study did not allow these pollutants to be measured or the assessment of the impact of indoor and outdoor pollution on respiratory symptoms.

To conclude, the prevalence of asthma symptoms, reported asthma attacks and self-reported asthma in adults of $>15$ yrs in rural Beijing, China, were very low compared with Western countries. The major determinants of reported asthma and asthma-like symptoms were age, sex and smoking habits.

Acknowledgements. The authors would like to thank A. Dybuncio and K. Noertjojo for the processing and analysis of data; C-S. Chou, Z-Q. $\mathrm{Ma}$ and the doctors in the villages who conducted the interviews; and J. Manfreda and members of the research team of the Canadian Lung Health Study for providing data for comparison.

\section{References}

1. Burney PGJ, Laitinen LA, Perdrizet S, et al. Validity and repeatability of the IUATLD (1984) Bronchial Symptoms Questionnaire: an international comparison. Eur Respir J 1989; 2: 940-945.

2. European Community Respiratory Health Survey. Variations in the prevalence of respiratory symptoms, self-reported asthma attacks, and use of asthma medication in the European Community Respiratory Health Survey (ECRHS). Eur Respir J 1996; 9: 687695.

3. Manfreda J, Becklake MR, Sears M, et al. Prevalence of asthma symptoms among adults aged 20-44 years in Canada. CMAJ 2001; 164: 995-1001.

4. Lai CKW, Chan JKW, Chan A, et al. Comparison of the ISAAC video questionnaire (AVQ3.0) with the ISAAC written questionnaire for estimating asthma 
associated with bronchial hyperreactivity. Clin Exp Allergy 1997; 27: 540-545.

5. Wong GW, Hui DS, Chan HH, et al. Prevalence of respiratory and atopic disorders in Chinese schoolchildren. Clin Exp Allergy 2001; 3: 1225-1231.

6. The International Study of Asthma and Allergies in Childhood (ISAAC) Steering Committee. Worldwide variations in the prevalence of asthma symptoms: the International Study of Asthma and Allergies in Childhood (ISAAC). Eur Respir $J$ 1998; 12: 315-335.

7. Braun-Fahrlander $\mathrm{CH}$, Gassner $\mathrm{M}$, Grize $\mathrm{L}$, et al. Prevalence of hay fever and allergic sensitization in farmers' children and their peers living in the same rural community. Clin Exp Allergy 1999; 29: 28-34.

8. Von Ehrenstein OS, Von Mutius E, Illi S, Baumann L, Bhm O, von Kries R. Reduced risk of hay fever and asthma among children of farmers. Clin Exp Allergy 2000; 30: 187-193.

9. Riedler J, Eder W, Oberfield G, Schreuer M. Austrian children living on a farm have less hay fever, asthma and allergic sensitization. Clin Exp Allergy 2000; 30: 194-200.

10. Ernst P, Cormier Y. Relative scarcity of asthma and atopy among rural adolescents raised on farms. Am J Respir Crit Care Med 2000; 161: 1563-1566.

11. Kilpelainen M, Terho EO, Helenius H, Koskenvuo M. Farm environment in childhood prevents the development of allergies. Clin Exp Allergy 2000; 30: 201208.

12. Martinez FD. Maturation of immune responses at the beginning of asthma. J Allergy Clin Immunol 1999; 103: 355-361.

13. Holt PG, Sly PD, Bjorksten B. Atopic versus infectious diseases in childhood: a question of balance. Pediatr Allergy Immunol 1997; 8: 53-58.

14. Strachan DP. Hay fever, hygiene, and household size. BMJ 1989; 299: 1259-1260.

15. Lai CKW, Douglas C, Ho SS, et al. Asthma epidemiology in the Far East. Clin Exp Allergy 1996; 26: 5-12. 